\title{
Application of Shark Teeth-Derived Bioapatites as a Bone Substitute in Veterinary Orthopedics. Preliminary Clinical Trial in Dogs and Cats
}

\section{OPEN ACCESS}

Edited by:

Fausto Cremonesi,

University of Milan, Italy

Reviewed by:

Marco Patruno,

University of Padua, Italy

Alix Kay Berglund,

North Carolina State University,

United States

${ }^{*}$ Correspondence:

Mario García-González

Mariog.gonzalez@usc.es

Specialty section:

This article was submitted to Veterinary Regenerative Medicine,

a section of the journal

Frontiers in Veterinary Science

Received: 18 June 2020

Accepted: 21 September 2020

Published: 28 October 2020

Citation:

García-González M, Muñoz

Guzón FM, González-Cantalapiedra A,

González-Fernández PM, Otero

Pérez $R$ and Serra Rodríguez JA

(2020) Application of Shark Teeth-Derived Bioapatites as a Bone Substitute in Veterinary Orthopedics. Preliminary Clinical Trial in Dogs and Cats. Front. Vet. Sci. 7:574017. doi: 10.3389/fvets.2020.574017

\begin{abstract}
Mario García-González ${ }^{1 *}$, Fernando María Muñoz Guzón ${ }^{1}$, Antonio González-Cantalapiedra ${ }^{1}$, Pío Manuel González-Fernández ${ }^{2}$, Rafael Otero Pérez ${ }^{3}$ and Julia Asunción Serra Rodríguez ${ }^{2}$

${ }^{1}$ Clinical Sciences Department, Veterinary Faculty, University of Santiago de Compostela, Lugo, Spain, ${ }^{2}$ New Materials Group, Department of Applied Physics, University of Vigo, Galicia Sur Health Research Institute (IISGS), Vigo, Spain,

${ }^{3}$ Traumatology and Orthopedic Surgery Unit, POVISA Hospital, Vigo, Spain
\end{abstract}

Background: The autograft is still considered the gold standard for the treatment of bone defects. However, given the significant morbidity of the donor site with which it has been associated, alternative substitutes for bone grafts have been developed. In the present study, a bone substitute composed of CaP biphasic bioceramics obtained from shark teeth was used (BIOFAST-VET).

Objective: The objective of this study is to evaluate the efficacy of a marine bioapatite in the veterinary clinical field using it as a bone-grafting scaffold in dogs and cats.

Methods: The biomaterial was randomly distributed in 6 veterinary clinical centers in Spain and was used in 24 cases (20 dogs and 4 cats) including 14 fractures, 9 arthrodesis, and 1 bone cyst. Grains between 500 and 2,000 $\mu \mathrm{m}$ were used. Inclusion and exclusion criteria were established. The time of consolidation and functional recovery were quantitatively and qualitatively assessed. For this, a follow-up was carried out at 2 , 4,8 , and 12 weeks, included radiographic images, physical examination and sharing the feedback with the owners.

Results: Nineteen cases completed the study (18 dogs and 1 cat; 11 fractures, 7 arthrodesis, and 1 bone cyst). The remaining five were excluded because they did not complete the radiographic follow-up (three cats and two dogs), being three arthrodesis and two fractures. In 18 of 19 cases, the use of the biomaterial was successful; the remaining one failed due to causes not related to the biomaterial. There were no systemic or local adverse reactions. Eighteen patients had a good functional recovery. The average consolidation time was 5.94 weeks in dogs with fractures and arthrodesis, not finding statistically significant differences between sex, weight, and procedure.

Conclusions: This biomaterial is presented as a very suitable candidate for orthopedic surgery in the veterinary field. Preliminary results showed that its use reduces consolidation time in dogs with fractures and arthrodesis. In addition, no adverse systemic or local reactions have been observed derived from its use.

Keywords: hydroxyapatite, $\beta$-tricalcium phosphate, biomaterials, bone regeneration, bone substitutes, veterinary orthopedics, marine bioapatites 


\section{INTRODUCTION}

Bone grafts are currently very required in orthopedic medicine and dental and maxillofacial surgery for regenerating, repairing, or replacing dental pieces or bone defects. Among the main applications of bone fillings are the reconstruction of missing bone cavities, congenital malformations, or bone atrophies. Moreover, they are used to promote bone regeneration in traumatic tissue damage or injuries (1). In maxillofacial and dental surgery, bone graft scaffolds are commonly used to contribute to the suitable environment for periodontal regeneration and maxillary sinus elevation, to repair defects after teeth extraction and/or in cases of implant placement (2-4).

In the veterinary orthopedics field, the gold standard is still the utilization of fresh cancellous bone grafts for enhancing defect healing. However, over the past two decades, the application of artificial bone grafts has been augmenting (5).

Allogeneic (cadaveric) grafts and deproteinized (xenogenic) bovine bone grafts are also used because of their greater osteoconduction, along with the mechanical performance of repairing tissues (1).

In the case of allografts, they have been mostly used as substitutes for autogenous bone grafts, but low bone fusion rate and risk of disease transmission have been observed as significant problems (6). Deproteinized bovine bone has shown excellent properties because of its excellent osteoconductive capacity and biocompatibility (7), as well as a long-term remain within the matrix of the host bone (8).

These evidences justify continued sacrifices to develop effective synthetic substitutes for bone grafting. The discovery of calcium phosphate ceramics and other related biomaterials has provided a better control of the resorption process improving the capacity of the materials in the bone regeneration (4).

Hydroxyapatite (HA) is the principal inorganic constituent of vertebrate bone, and it is also lodged in the dentin and tooth enamel (9). The characteristics of HA have been investigated for several decades. Posner et al. (10) proposed its crystalline structure from the analysis of a monocrystal (11). Its ionic character makes it a stiff, refractory (12), and insoluble ceramic (13), with a melting point higher than $1,500^{\circ} \mathrm{C}$ (12).

This calcium phosphate, which can be acquire synthetically, has properties of biocompatibility, non-toxicity, chemical stability, osteoconduction, and bioactivity. Such properties make the material very practical for medical uses. HA can be used as a replacement for small parts of bone, reinforcement in composite materials, cavity filling in dentistry, and coating of metal surfaces for implants $(14,15)$.

Synthetic sources, as opposed to natural ones, in addition to the good results regarding osseointegration, provide high availability, innate reproducibility, and versatility to be integrated in concrete formulations for specific applications. Thereby, Landi et al. (16) revealed the HA has a high potential as a bone substitute replaced with strontium and magnesium in the cellular reply

\footnotetext{
Abbreviations: $\mu \mathrm{m}$, micrometer; ${ }^{\circ} \mathrm{C}$, degrees Celsius; BMP, bone morphogenetic proteins; BV, BIOFAST-VET; h, hour; HA, hydroxyapatite; Hz, Hertz; kg, kilogram; $\mathrm{mm}$, millimeter; min, minute; $\mathrm{P}$, significance level; TCP, tricalcium phosphate.
}

(16). Composite materials were proposed as another strategy to increase osteoconductivity and biocompatibility, providing an adequate resorption, like Shih et al. (17), who have tested bone generation in animal models with HA and resorbable dehydrated calcium sulfate (17). Chazono et al. (6) got a high apposition rate of minerals in rabbit bone defects of highly pure b-tricalcium phosphate $(\beta-\mathrm{TCP})$ powder mixed with hyaluronic acid, compared to pure $\beta$-TCP in blocks (6). Bioactive glasses are very active materials that induce positive regulation of genes related to differentiation and osteoblast proliferation. As a result, they have excellent biological behavior, thanks to their osteoconductive characteristics $(18,19)$.

Some case reports provided details about the use of different bone substitutes in the veterinary field. One of this is a successful correction of a bone deformity where the distal tibia is turned inward toward the body (pes varus) in two Teckels. For this, a synthetic $\beta$-TCP wedge was used to fill in defects made with osteotomies. Eight weeks after the intervention, the bone was integrated. The TCP blocks were entirely resorbed after 4 months, and remodeling at the osteotomy site was observed $(20,21)$.

In another investigation, another method was used mixing $\beta$ TCP granules with the patient's own blood and was used as a bone substitute in defects located in long bones of 13 patients (22). The treatment of an atrophic non-union in the distal radius area of a Yorkshire Terrier was also investigated, using a three-dimensionally printed $\beta$-TCP scaffold with morphogenetic proteins (22).

Nowadays, numerous investigations are being carried out to obtain biomaterials of marine origin. The fibrillar collagen of the sea urchin has been shown to be a very valuable biomaterial for the production of skin-like scaffolds (23). Recent researches have demonstrated the possibility of obtaining bone substitutes of marine origin, BIOFAST-VET (BV). This novel product was designed to repair and regenerate bone tissue. It is made from a ceramic material obtained from the reassessment of a fish byproduct, shark teeth (Prionace glauca). It is a very abundant and low-cost raw material at present $(1,24)$.

The composition, morphology, and characterization (Raman and XRD techniques) of shark teeth-derived bioapatites have been studied $(1,24-28)$ and revealed a globular porous structure with biphasic composing $\sim 70 \%$ apatitic (HA, apatite-CaP, fluorapatite) and $\sim 30 \%$ non-apatitic phase (whitlockite, $\beta$-TCP), and contributions of $\mathrm{F}, \mathrm{Na}$, and $\mathrm{Mg}$. This composition and structure promoted a significantly higher bone mineral density in a rodent model after 3 weeks of healing compared with a commercial artificial biphasic HA/ $\beta$-TCP $(60 \% / 40 \%)$ bone graft $(P<0.05)$. In addition, $1-\mathrm{mm}$ marine bioceramics developed higher osteointegration and horizontal growth of bone tissue at the central area of the defect $(1,28)$.

A new advantage is that this biomaterial is environmentally friendly, because it is a natural product, gives value to fish waste, and reduces the risk of disease transmission, as it comes from a species phylogenetically far from our domestic species. Viewing the promising results (histological and radiographic) obtained in an in vivo study carried out on rodents (1), the mean goal of this research is to evaluate the capacity of this compound as a bone substitute in the veterinary clinical field, being used in 
several orthopedic procedures in dogs and cats, trying to avoid the complications derived from the non-union.

\section{METHODS}

\section{Biomaterial Obtaining Method}

The fabrication method of the bone substitute of marine origin $\mathrm{BV}$ is based on pyrolytic techniques in order to remove the organic compounds. The natural precursor (shark teeth $P$. glauca) is heated to $950^{\circ} \mathrm{C}$ for $12 \mathrm{~h}$ using a heating ramp of $2^{\circ} \mathrm{C}$ $\mathrm{min}^{-1}$ and a cooling ramp of $20^{\circ} \mathrm{C} \mathrm{min}^{-1}$, as described elsewhere $(1,24)$. Once pyrolyzed, the powders were subjected to a sieving process to select macrogranules in the diameter ranges of 0.5 to $1.0 \mathrm{~mm}, 1.0$ to $2.0 \mathrm{~mm}$, and 2.0 to $3.0 \mathrm{~mm}$. The sterilization method used was gamma radiation (Aragogamma S.L.) $(1,24)$.

\section{Study Design}

The study was designed by a multidisciplinary group made up of researchers from the School of Industrial Engineering of Vigo (PM and JA) and the Faculty of Veterinary Medicine of Lugo (A, FM, and $\mathrm{M}$ ), with the collaboration of specialists in human orthopedic surgery (R). The material had previously passed biocompatibility tests and a complete histological evaluation in preclinical studies $(1,24,28)$. The initial approach was to elucidate in which clinical situations the material object of study would be useful. Once a consensus was reached, the data collection method was designed. Afterward, a veterinary centers, clinics, and hospitals list in Spain was compiled, with sufficient orthopedic casuistry that could be included in the study. Randomly, six were selected (CV Miralbueno, Hospital Veterinario Vetpets, Hospital Veterinario Lepanto, CV Fauna, CV Sauces, CV El Parque). Because of the randomization, the sample of veterinary centers chosen is heterogeneous in terms of the age of the veterinary team, medical equipment, knowledge, and geographical location.

All of them were provided with the available documentation about the biomaterial, and the handling protocol was explained to the staff. Material of different grain sizes (diameter range $=$ $500-1,000$ and $1,000-2,000 \mu \mathrm{m}$ ) was supplied to facilitate its use and adapt it to the size of the defect to be filled. They were also provided with a list of techniques in which the use of BV would be indicated.

At the end of each procedure, the veterinarians had to fill out a form (Supplementary Material 1) about the clinical use of the biomaterial (one per case). The results of this survey, along with the x-rays, were analyzed and compared by a committee of two outside blind experts who came to a consensus about whether the evolution was satisfactory or not.

\section{Clinical Cases and Criteria Selection}

The legal owners of the animals signed an informed consent about the use of BV as a part of the treatment.

Twenty-four clinical cases (20 dogs and 4 cats) have been reported in which bone substitute of marine origin has been used to improve bone healing and fill critical defects. Fourteen of the cases were treatment of fractures, nine arthrodesis, and a benign bone cyst.
The patients were selected strictly according to their clinical status and a set of established criteria: patients of any age, sex, or weight; without any disease or systemic infection; and skeletally mature. The exclusion criteria were disease or systemic infection, malignant tumors, severe renal dysfunctions, a greater anesthetic risk, and animals with uncontrolled bone metabolism.

\section{Radiographic Evaluation}

Radiographic images were taken before surgery to evaluate the injury and, shortly after, to evaluate the success of the procedure. To assess the evolution of the patients' progress, radiographic assessments were performed at 2, 4, 8, and 12 weeks after the surgery. Two radiographic views were made (anteroposterior and lateral). The follow-up consultations included a general physical examination, control radiographs, and feedback with the client to monitor the process. Each radiograph was evaluated by a stage score of 1 to 5 points to set the consolidation time (1: not visible callus formation; 2: barely visible callus formation; 3 : scattered, not homogeneous callus; 4: uniform, mature callus formation; 5: very active, hyperthrophic callus formation) (29). The results were evaluated by the veterinary specialist of the entity and later by a panel of two blind outside experts.

\section{Epidemiological Survey}

An epidemiological survey (Supplementary Material 1), as stated above, was sent to all the veterinarians for each case, including the patients' clinical history (anamnesis, diagnosis, surgical treatment, and progress), functional recovery and information related to the biomaterial and its handling (grain size used, difficulty in using it, mixing with another material or substance, advantages over other fillings), and a radiographic report. Finally, the veterinarians provided a final report on their experience in the clinical use. Later, the obtained information was reviewed by a panel of blind independent experts to see the suitability of the treatment and its correct evolution.

\section{Functional Recovery}

Functional recovery was evaluated by the clinicians of the centers in each revision, using a simple scale $(1-9,11-16)$ with three levels: good (12-16), regular $(6-9,11)$, and poor (1-5), indicating total, partial, and no recovery of function, respectively. The criteria that were evaluated were as follows: lameless, pain on palpation, and weight-bearing (Table 1) $(30,31)$.

\section{Statistical Analysis}

A statistical analysis was carried out with the consolidation time in search of statistically significant differences regarding sex (males and females), weight (three groups: (a) $<5 \mathrm{~kg}$, (b) $5-$ $20 \mathrm{~kg}$, (c) $>20 \mathrm{~kg}$ ), and procedure (internal or external fixation and arthrodesis).

Statistical analysis was performed with the computer program SigmaPlot ${ }^{\circledR} 12.5$ for Windows (Systat Software Inc., San José, CA, United States). A value of $p<0.05$ was considered statistically significant. The descriptive study of the population was shown as the mean $\pm \mathrm{SD}$. The normality of variances was assessed using the Shapiro-Wilk test. To determine the differences between the groups for non-categorical variables 
TABLE 1 | Functionality recovery scoring system for assessing patients (30, 31).

\begin{tabular}{lll}
\hline Criteria & Score & Clinical evaluation \\
\hline Lameless & 1 & Not walk \\
& 2 & Severe limp when walking \\
& 3 & Moderate limp when walking \\
& 4 & Slight limp when walking \\
Pain on & 5 & No limp. Walk normally \\
palpation & 2 & Patient cannot be palpated \\
& 3 & Moderate signs; patient pulls limb away \\
& 4 & Mild signs; patient turns head in recognition \\
Weight- & 1 & Non-weight-bearing standing and walking \\
bearing & 5 & None \\
& 2 & Partial weight-bearing standing; non-weight-bearing walking \\
& 3 & Partial weight-bearing standing; non-weight-bearing walking \\
& 4 & Normal standing; favors affected limb when walking \\
& 5 & Equal on all limbs standing and walking \\
& &
\end{tabular}

(weight), a one-way analysis of variance was done. Categorical variables (sex and procedure) were assessed using $t$-test and one-way analysis of variance.

\section{RESULTS}

Nineteen cases completed the study (18 dogs and 1 cat; 12 males and 7 females; 11 fractures, 7 arthrodesis, and 1 bone cyst) (Table 2). The remaining five were excluded because they did not complete the radiographic follow-up (three cats and two dogs; three arthrodesis and two fractures). The age of the canine patients ranged from 1 to 15 years (average age of 7 years), being 10 males and 8 females, with weight ranging from 2.5 to $36 \mathrm{~kg}$ (average of $16.4 \mathrm{~kg}$ ). The feline patient was a 3 -yearold male and of $3.5-\mathrm{kg}$ weight. In all cases except for one (case 11 ), the functional recovery was good, and no complications were recorded.

The statistical analysis was carried out only in dogs, because the sample in cats was finally not representative (one case), and only with arthrodesis and fractures (with external and internal fixation). Given the hypothesis whether sex or weight influences the time of consolidation, no statistically significant differences were found. Also, no statistically significant differences were found when comparing the procedures made (Table 3).

The bone substitute of marine origin (Figure 1) was applied mixed with the patient's own blood, previously extracted. In all cases, BV was used to improve bone healing, fill in critical defects, and complement the recommended procedures.

The suitability of the bone substitute of marine origin was studied in different types of orthopedic pathologies in veterinary field. In specific, BV was used as a bone substitute and to perfect traditional methods (bone defects caused by cysts, external and internal fixation of breakages, and arthrodesis).
In all of the cases, there were no reports on adverse reactions at the grafting site or at systemic level related to biomaterial. Except for case 11, there were no records of postoperative infection or foreign body reaction, regardless of the amount of grafted material. In case 11, because it was an old fracture by firearm and remitted from a less specialized clinic, the infection was not treated properly from the beginning, and the filling was not successful, producing a fistula after 2 weeks. The group that reviewed the case considered that, in this case, the use of the biomaterial had been contraindicated.

The efficacy of surgical treatments was performed by clinical examination and radiographic evaluation at the times established. In most of the successful cases, postsurgical $\mathrm{x}$ ray controls indicated high rates of bone regeneration, being the mean consolidation time 5.94 weeks (ranging from 4 to 9 weeks). Except in case 11, all the bone defects healed without complications 12 weeks after the procedure.

The retrospective study of the questionnaire revealed that all the veterinarians who used BV agreed that it was an easy to use biomaterial. They asserted that the consolidation time was reduced, as well as the acceleration of joint fusions in cases of arthrodesis.

\section{Clinical Cases Description}

Clinical Case 1. Dog, English setter breed, female of $30 \mathrm{~kg}$, presented by an old failure due to a panarthrodesis infection with stepped plate in the carpal joint. It was decided to place a titanium plate on the dorsal side, using two crossed needles and a BV graft. The results were good, and the bone substitute helped the bone to consolidate faster (Figure 2).

Clinical Case 2. Dog, German shepherd breed, adult male of $35 \mathrm{~kg}$, presented an old fracture ( 3 months) of two metatarsals. We performed tarsometatarsal arthrodesis from the calcaneus to the metatarsals by a lateral approach and using a BV graft. The radiographic evaluation and the clinical examination were performed up to 8 weeks, a good and effective osseointegration being observed.

Clinical Case 3. Dog, Yorkshire breed, adult, male of $2.5 \mathrm{~kg}$, presented a distal third fracture of the radius and ulna. An external type II fixator with five metallic thread needles and a BV graft is placed in the fracture site. It is a case in which the external fixation is not ideal, since the literature (32-35) describes the possibility of a non-union in fractures of the third distal of the radius in small breeds, being able to cause deformations, and requiring new procedures and even amputations. The use of the bone graft of marine origin resulted in rapid ossification of the fracture, within 4 weeks after the surgery, a complete ossification being observed at the fracture site at 6 weeks.

Clinical Case 4. Mixed-breed dog, adult, 15-kg male, presented a slightly comminuted transverse diaphyseal fracture of the ulnar and radius of the left limb. It was stabilized with an internal fixation plate and a BV graft at the fracture site. At 4 weeks, consolidation was observed, and at 6 weeks, the plate was removed. At 8 weeks, the fracture site was completely remodeled (Figure 3).

Clinical Case 5. Dog, Yorkshire breed, adult, male of $2.5 \mathrm{~kg}$, presented non-union in a distal third fracture of the radius and 
TABLE 2 | Summary of patients treated with BIOFAST-VET.

\begin{tabular}{|c|c|c|c|c|c|c|}
\hline No & $\begin{array}{l}\text { Species/Breed } \\
\text { Age/Gender/Weight }\end{array}$ & Orthopedic problem & Type of surgery & Grain size & $\begin{array}{l}\text { Consolidation time } \\
\text { (weeks) }\end{array}$ & $\begin{array}{l}\text { Functional recovery } \\
\text { and complications }\end{array}$ \\
\hline 1 & Dog/English Setter/10/F/30 kg & $\begin{array}{l}\text { Old failure due to an arthrodesis infection } \\
\text { with steppped plate in carpal joint }\end{array}$ & $\begin{array}{l}\text { Carpus } \\
\text { arthrodesis }\end{array}$ & $1-2 \mathrm{~mm}$ & 7 & Good, none \\
\hline 2 & Dog/German Shepherd/Adult/M/35 kg & 2 fractured metatarsals & Tarsal arthrodesis & $1-2 \mathrm{~mm}$ & 8 & Good, none \\
\hline 3 & Dog/Yorkshire/Adult/M/2.5 kg & Distal third fracture of radius and ulna & ESF & $1-2 \mathrm{~mm}$ & 4 & Good, none \\
\hline 4 & Dog/Crossbreed/Adult/M/15 kg & $\begin{array}{l}\text { Slightly comminuted diaphyseal fracture of } \\
\text { radius and ulna }\end{array}$ & ISF & $0.5-1 \mathrm{~mm}$ & 4 & Good, none \\
\hline 5 & Dog/Yorkshire/Adult/M/2.5 kg & Distal third fracture of radius and ulna & ISF & $0.5-1 \mathrm{~mm}$ & 5 & Good, none \\
\hline 6 & Dog/Crossbreed 1/F/13 kg & $\begin{array}{l}\text { Highly comminuted femoral diaphyseal } \\
\text { fracture }\end{array}$ & ESF Tie in & $1-2 \mathrm{~mm}$ & 6 & Good, none \\
\hline 7 & Dog/Crossbreed Adult/F/8 kg & Transverse fracture of radius and ulna & ISF & $1-2 \mathrm{~mm}$ & 4 & Good, none \\
\hline 8 & Dog/Crossbreed Adult/F/11 kg & Radius and ulna fracture & ISF & $0.5-1 \mathrm{~mm}$ & 8 & Good, none \\
\hline 9 & Dog/Crossbreed Adult-F-12kg & Intercondylar fracture & $\begin{array}{l}\text { ISF with } 2 \\
\text { condylar needles }\end{array}$ & $1-2 \mathrm{~mm}$ & 8 & Good, none \\
\hline 10 & Dog/Crossbreed Adult/M/12 kg & Tibia and fibula fracture & ISF & $1-2 \mathrm{~mm}$ & 7 & Good, none \\
\hline 11 & Dog/Crossbreed Adult/M/16 kg & Old femoral fracture by firearm & ISF & $1-2 \mathrm{~mm}$ & - & $\begin{array}{l}\text { Poor, infection and } \\
\text { biomaterial expulsion }\end{array}$ \\
\hline 12 & Dog/German Shepherd/8/M/36 kg & $\begin{array}{l}\text { Highly comminuted open fracture of the } \\
\text { tibia }\end{array}$ & Tarsal arthrodesis & $1-2 \mathrm{~mm}$ & 4 & Good, none \\
\hline 13 & Dog/Teckel 2-F/10 kg & Benign bone cyst & $\begin{array}{l}\text { Bone biopsy and } \\
\text { defect filling }\end{array}$ & $0.5-1 \mathrm{~mm}$ & 8 & Good, none \\
\hline 14 & Dog/Crossbreed/8/F/3 kg & Open tibial and tarsal fracture & Tarsal arthrodesis & $1-2 \mathrm{~mm}$ & 8 & Good, none \\
\hline 15 & Dog/Boxer $1.5 / \mathrm{M} / 29 \mathrm{~kg}$ & $\begin{array}{l}\text { Severe injuries to the tendons of the tarsal } \\
\text { joint }\end{array}$ & Tarsal arthrodesis & $1-2 \mathrm{~mm}$ & 6 & Good, none \\
\hline 16 & Dog/Boxer 1.5/M/29 kg & $\begin{array}{l}\text { Severe distal third injuries to the radius, } \\
\text { carpus and metacarpus }\end{array}$ & $\begin{array}{l}\text { Radial, carpal and } \\
\text { metacarpal } \\
\text { panarthrodesis } \\
\text { with circular ESF }\end{array}$ & $1-2 \mathrm{~mm}$ & 6 & Good, none \\
\hline 17 & Cat/European Common/3/M/3.5 kg & Tibial fracture & ESF & $1-2 \mathrm{~mm}$ & 4 & Good, none \\
\hline 18 & Dog/English Setter/3/M/27 kg & Severe radiocarpal joint injuries & Carpal arthrodesis & $1-2 \mathrm{~mm}$ & 8 & Good, none \\
\hline 19 & Dog/Crossbreed/14/M/17 kg & Multifragmentary femoral fracture & Double ISF & $1-2 \mathrm{~mm}$ & 8 & Good, none \\
\hline
\end{tabular}


ulna, a relatively large isolated bone fragment being observed. An internal fixation plate was placed, the necrosed bone fragment is removed, and BV graft was added to keep the length of the bone. The bone substitute provided a faster consolidation of the fracture. Eight weeks later, radiographs revealed a complete ossification of the fracture site.

Clinical Case 6. Mixed-breed dog, female of $8 \mathrm{~kg}$ and 1 year old, presented a highly comminuted femoral diaphyseal fracture in the left posterior limb. It was a complex fracture in a growing dog, which occurred 5 days before the procedure. It was decided to perform a functional reduction and stabilized the fracture with an external tie-in fixator and a BV graft. Two weeks later, an early ossification was radiographically observed, integrating the graft grains perfectly into the new tissue.

Clinical Case 7. Mixed-breed dog, adult, female of $8 \mathrm{~kg}$, presented malunion of a transverse fracture of radius and ulna in the left anterior limb. Non-functional bone tissue formation

TABLE 3 | Statistical parameters about the time of consolidation compared with the sex, weight, and procedure ( $p<0.05$ was considered statistically significant).

\begin{tabular}{|c|c|c|c|}
\hline & Variable & Mean and SD (weeks) & $p$ \\
\hline \multirow[t]{2}{*}{ Sex } & Males & $6 \pm 1.7$ & \multirow{2}{*}{0.233} \\
\hline & Females & $7 \pm 1.52$ & \\
\hline \multirow[t]{3}{*}{ Weight } & Group (a): < $5 \mathrm{~kg}$ & $5.67 \pm 2.08$ & \multirow{3}{*}{0.714} \\
\hline & Group (b): 5-20 kg & $6.63 \pm 1.77$ & \\
\hline & Group (c): > 20 kg & $6.50 \pm 1.52$ & \\
\hline \multirow[t]{3}{*}{ Procedure } & Fractures Internal fixation & $6.14 \pm 1.77$ & \multirow{3}{*}{0.433} \\
\hline & External fixation & $5.00 \pm 1.41$ & \\
\hline & Arthrodesis & $6.71 \pm 1.50$ & \\
\hline
\end{tabular}

was observed. The fragments were separated with a surgical saw and aligned correctly. Finally, an internal fixation plate and BV graft were placed to favor the ossification process. The patient evolved favorably. At 7 weeks, a remarkable advance in the radial ossification process was observed radiographically. The filling was practically reabsorbed and integrated into the new tissue. The ulna did not ossify because it was not correctly aligned (Figure 4).

Clinical Case 8. Mixed-breed dog, adult, female of $11 \mathrm{~kg}$, presented a radius and ulna fracture. After studying the situation, it was decided to use an internal fixation with a locking plate and a BV graft in the fracture center. Eight weeks later, radiographs showed a complete ossification of the fracture site.

Clinical Case 9. Mixed-breed dog, adult, female of $12 \mathrm{~kg}$, presented an intercondylar humerus fracture of the left forelimb. The fracture was stabilized by placing two needles and an internal fixation plate with the BV graft. Radiographs revealed a correct evolution and consolidation at 7 weeks.

Clinical Case 10. Mixed-breed dog, adult, male of $12 \mathrm{~kg}$, presented a fracture of the tibia and fibula. It proceeded to stabilize the tibia fracture using an internal fixation plate with six screws. In this case, no follow-up radiographs are available, but the owners stated that the animal had been using the paw for support and did not show any pain 2 weeks after the procedure.

Clinical Case 11. Mixed-breed dog, adult, male of $16 \mathrm{~kg}$, presented an old humerus fracture by firearm. Fractures caused by firearm represent a delicate situation in traumatology (36). In general, they are contaminated, so they tend to become infected, being complicated to treat. In this case, the fracture was old, and the patient was referred from a poorly specialized clinic where an attempt has been previously made to stabilize the fracture with an external fixator. The fracture was stabilized with an internal fixation plate and a BV graft aimed at promoting ossification.

\section{$\mathbf{A}$}

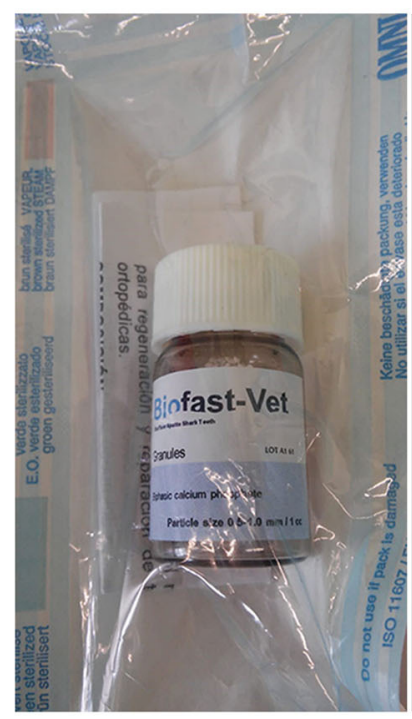

B

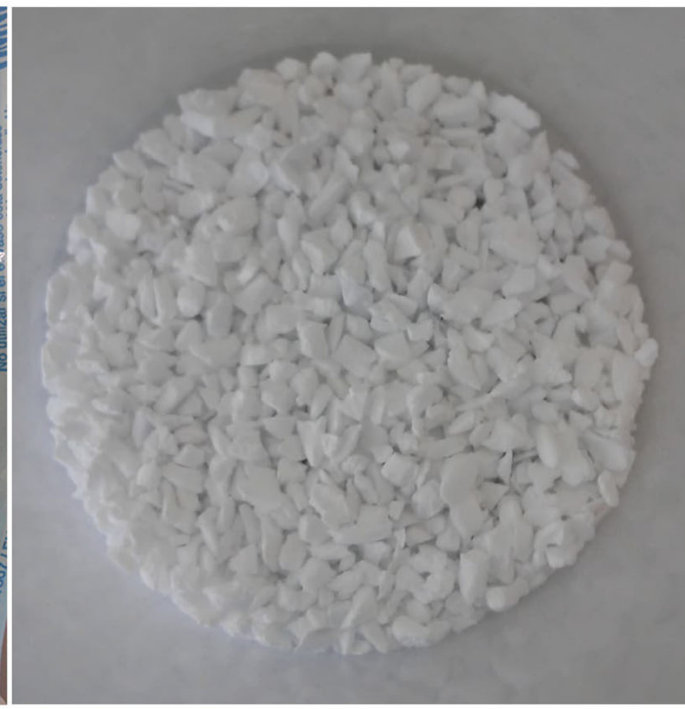

C

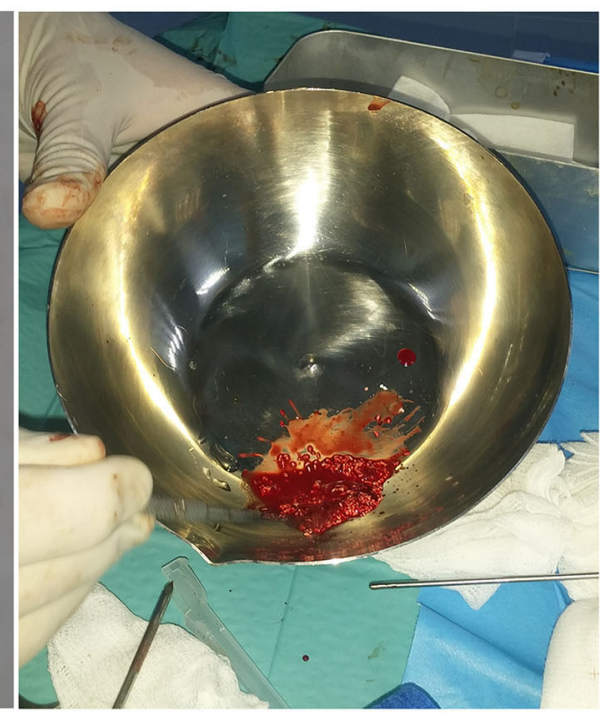

FIGURE 1 | Biomaterial vial (A), biomaterial granules (B), preparation of the biomaterial mixture for intraoperative application with autologous blood (C). 
A

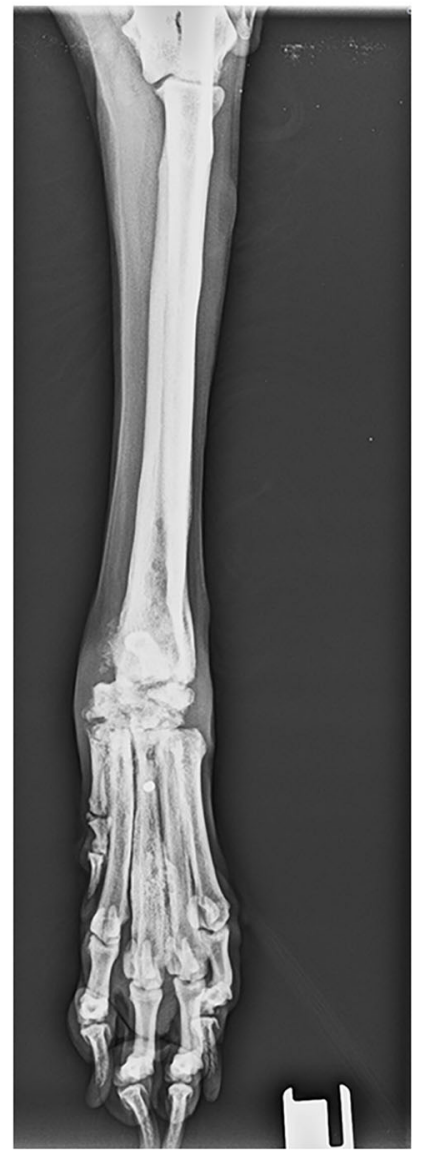

B

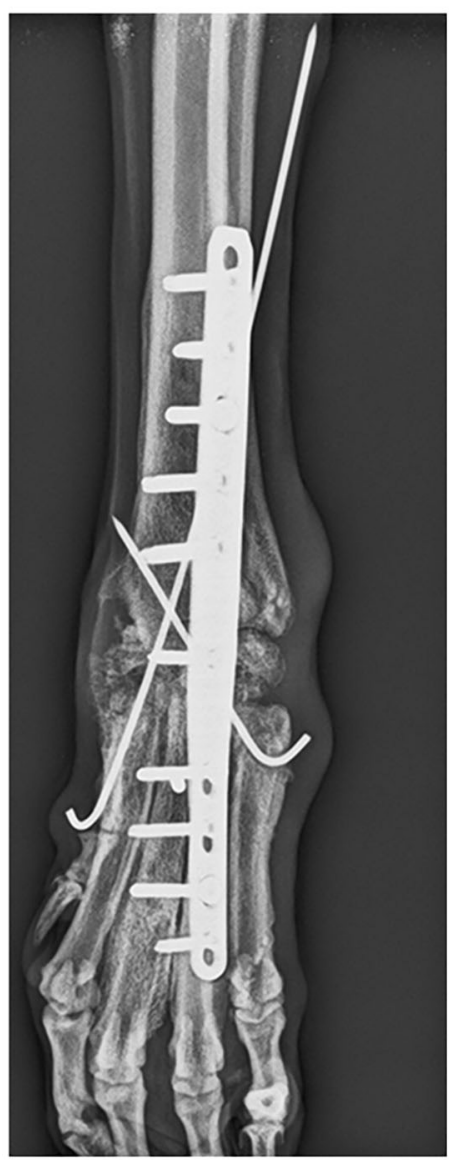

C

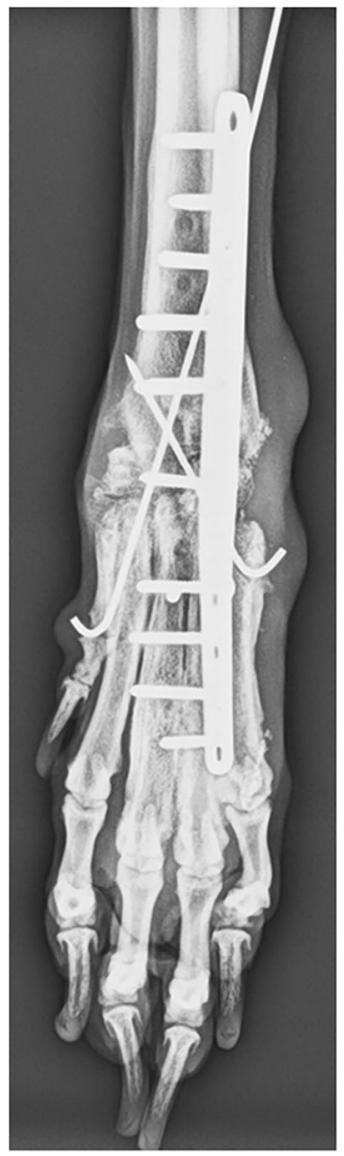

D

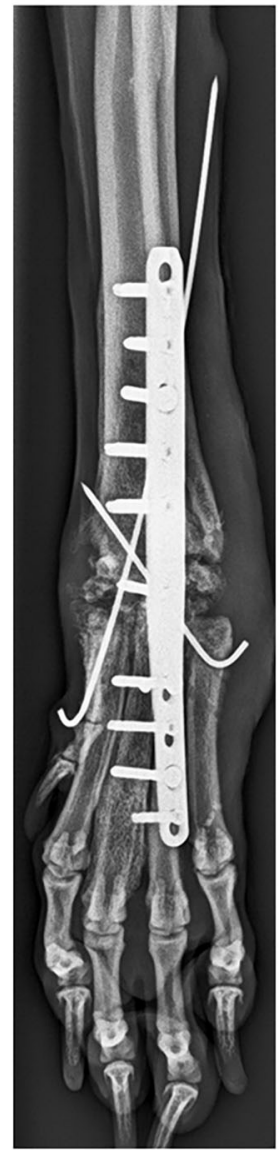

FIGURE 2 | Case 1. Dorsopalmar radiographic images of the carpal joint infection. Preoperative radiographic image (A); postoperative radiographic image (B); Postoperative control 4 weeks after surgical procedure (C); postoperative control 12 weeks after surgical procedure (D).

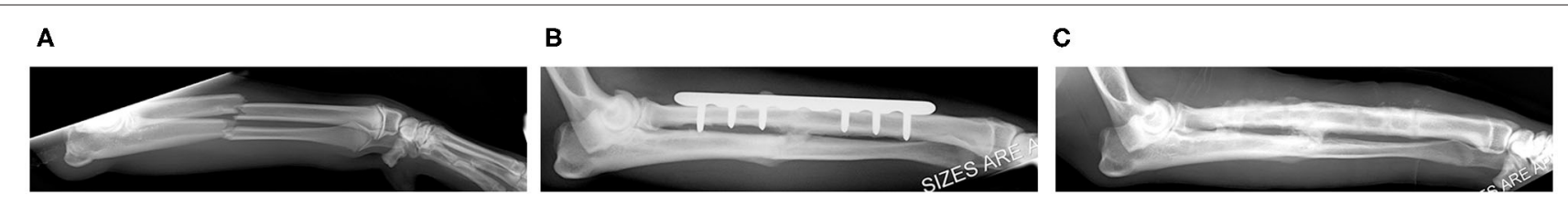

FIGURE 3 | Case 4. Mediolateral and laterolateral radiographic images of radius and ulna fracture. Preoperative radiographic image (A); postoperative control 4 weeks. Consolidation is observed (B); postoperative control 8 weeks. Remodeling is observed (C).

Unfortunately, after 2 weeks, the infection continued, and the bone substitute was expelled from the body with the suppuration. In this case, the use of BV did not have any result because the local infection had not been properly treated well (Figure 5).

Clinical Case 12. Dog, German shepherd breed, male of $36 \mathrm{~kg}$, presented a highly comminuted open fracture of the tibia, with great destruction of soft tissue. In the first procedure, a wall locking plate was placed. A week after that, the patient presented an angular deviation of the limb and plantigradism, because the plate was bent because of the empty holes, and, in addition, presented a lesion of the Achilles tendon, with rupture of the deep flexor. Subsequently, it was proposed to solve everything with surgery. A custom hybrid plate was designed, with locking screws, to solve the angulation and achieve a tarsal, since it was 
A

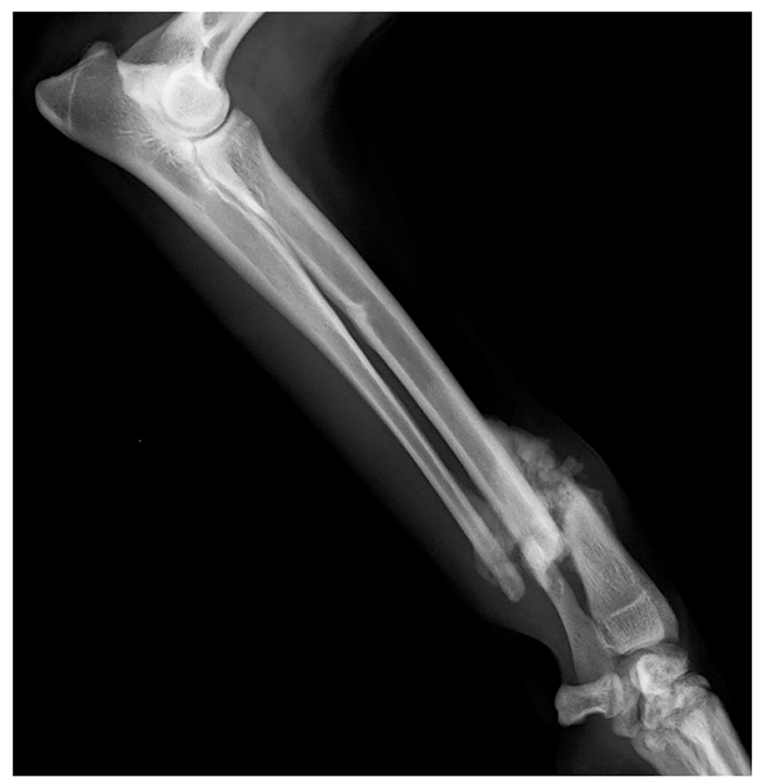

B

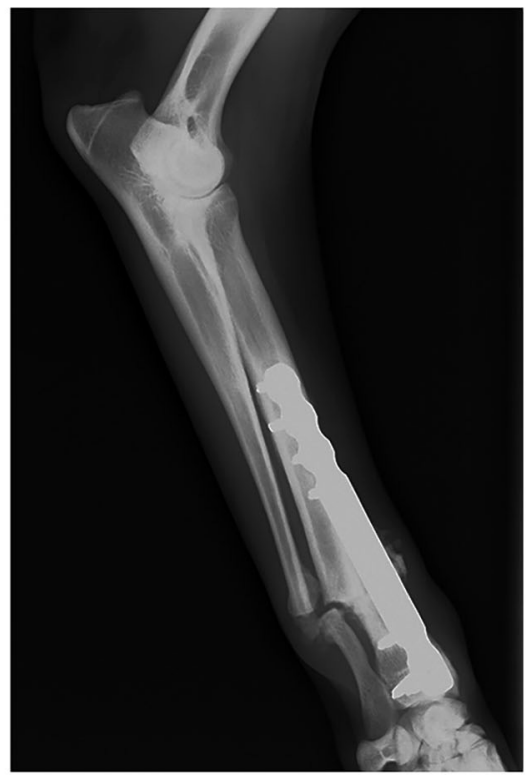

C

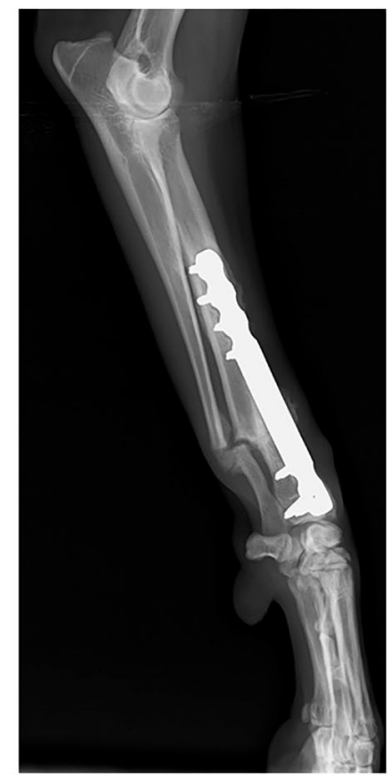

FIGURE 4 | Case 7. Mediolateral radiographic images of the radius and ulna fracture. Preoperative radiographic image (A); postoperative control 4 weeks (B); postoperative control 8 weeks. Remarkable ossification is observed. The material has been fully integrated and reabsorbed. The ulna is not ossifying because it was not aligned properly (C).

A

B

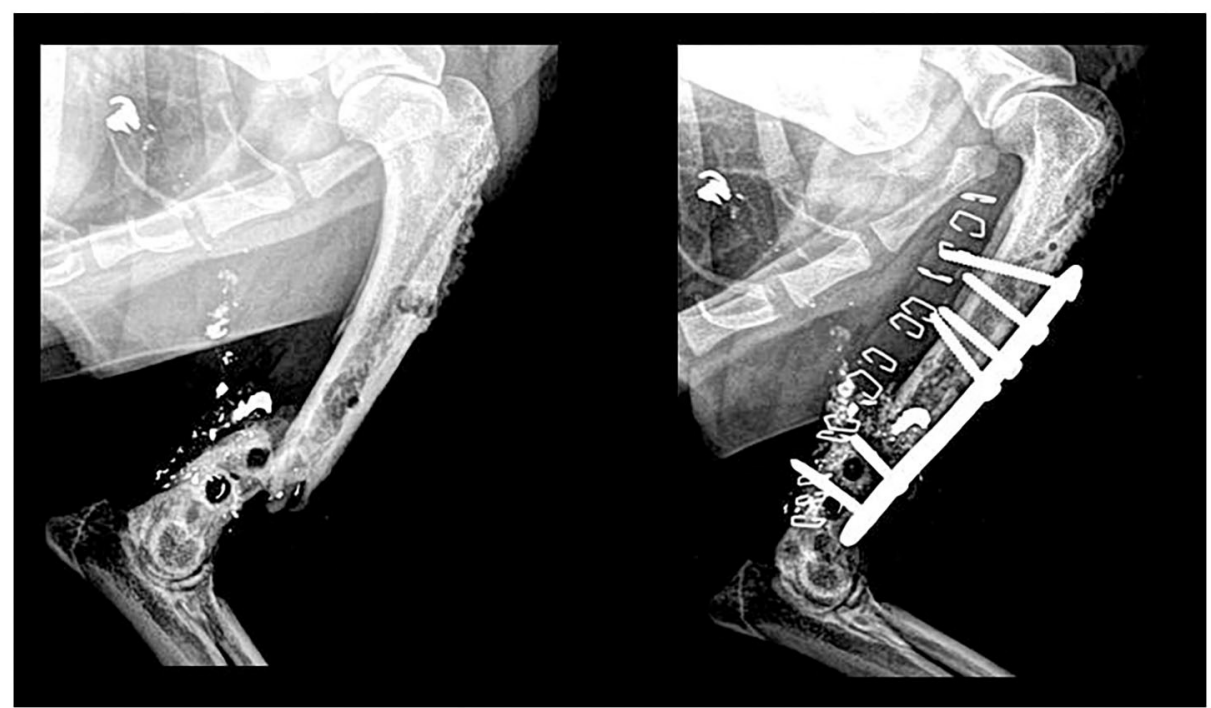

FIGURE 5 | Case 11. Mediolateral radiographic images of an old femoral fracture by firearm. Preoperative reintervention radiographic image (A); postoperative control 2 weeks. Suppuration and elimination of the biomaterial can be observed (B).

not possible to suture the tendon. The callus formed was broken to facilitate the alignment, and the BV graft was incorporated. The result was very good, an almost perfect alignment was achieved, and an almost perfect functionality was granted. Radiographs showed a complete ossification at 8 weeks (Figure 6).

Clinical Case 13. Dog, Teckel breed, female of $10 \mathrm{~kg}$, presented an expansive lesion in the distal metaphysis of the right 


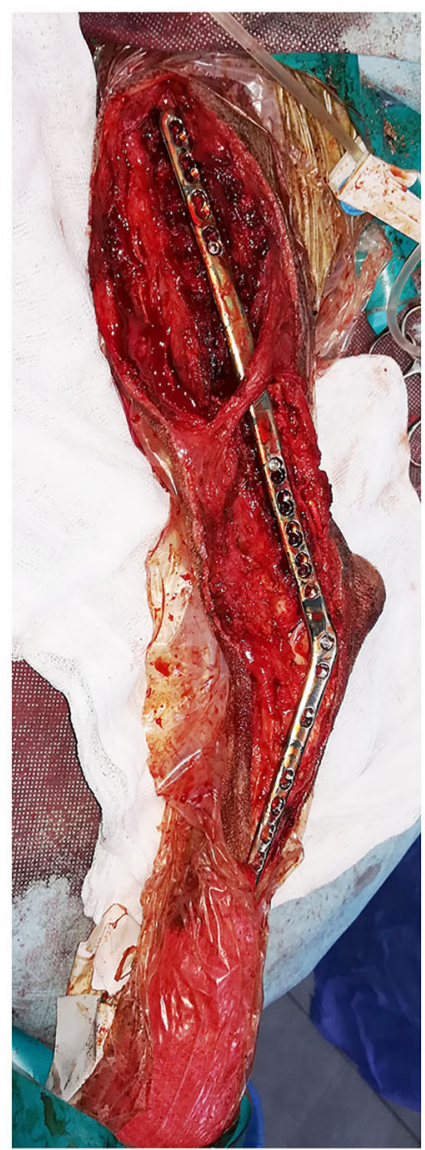

B

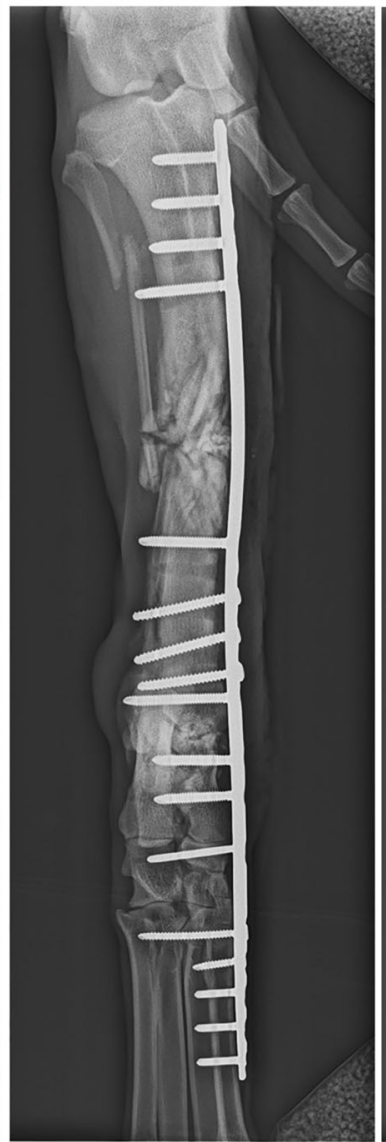

C

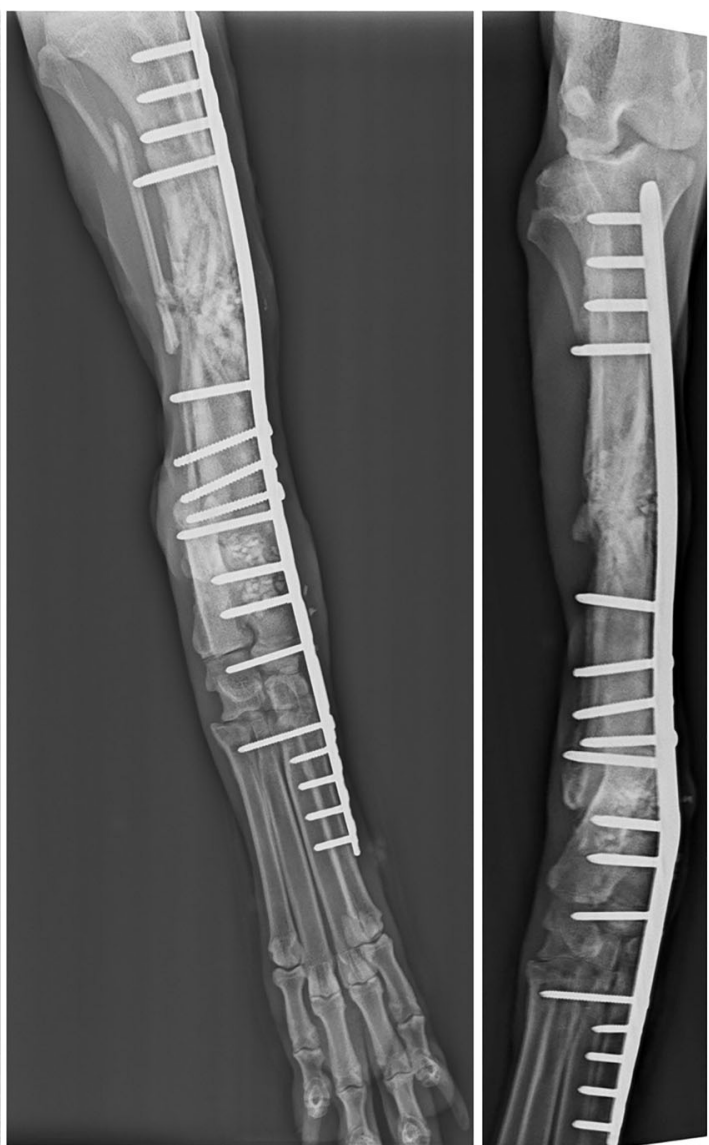

FIGURE 6 | Case 12. Highly comminute open fracture of the tibia correct by tarsal arthrodesis. Intervention (A); postoperative image (B); postoperative control 4 weeks (C); postoperative control 8 weeks, perfect ossification is observed (D).

humerus, with non-specific right axillary lymphadenopathy. Bone biopsy was performed, and a benign unicameral bone cyst was diagnosed. The defect was filled with a BV graft. Eight weeks later, radiographs showed good consolidation (Figure 7).

Clinical Case 14. Mixed-breed dog, female of $3 \mathrm{~kg}$, was hit by a car and could not stand its posterior limbs. Radiographs revealed a distal fracture of the right tibia, with several fragments that reach the tarsal joint, destabilizing the joint. In the left posterior limb, the patient presented hip dislocation. It was decided to perform arthrodesis of the joint with an internal fixation plate and a bone graft. Four weeks later, radiographs revealed good remodeling, which was complete 8 weeks after the procedure (Figure 8).

Clinical Cases 15 and 16. Dog, Boxer breed, female of $29 \mathrm{~kg}$, presented lesions in the left posterior limb, in the joint of the tarsus in the right posterior limb, and in the carpal joint in the right anterior limb.

- The left posterior limb had to be amputated because of irreversible injuries. An endoprosthesis and exoprosthesis was placed instead.
- In the right posterior limb, a partial arthrodesis of the joint was performed because of damage to the tendons. A BV graft was also placed.

- In the right anterior limb, there was no soft tissue coverage in the distal two-thirds of the radius. There was neither carpus nor metacarpals. An external fixator was placed; bandages and treatment were applied until the entire limb was covered with granulation tissue. At that point, a panarthrodesis was performed, using a circular fixator and a BV graft.

The use of BV provided very good results to accelerate the joint fusion because, in this case, there were three injured joints, and it was essential to achieve a quick consolidation to recover mobility as soon as possible. In addition, because of the serious soft tissue injuries, the implant of the right posterior limb was exposed, so it was vital to accelerate the consolidation to be able to remove the implant and thus allow the tissue recovery. In this sense, the use of BV was successful, allowing bearing weight normally on the affected limbs.

Clinical Case 17. Cat, European Common breed, male of $3.5 \mathrm{~kg}$, presented a fracture of the tibia. We 


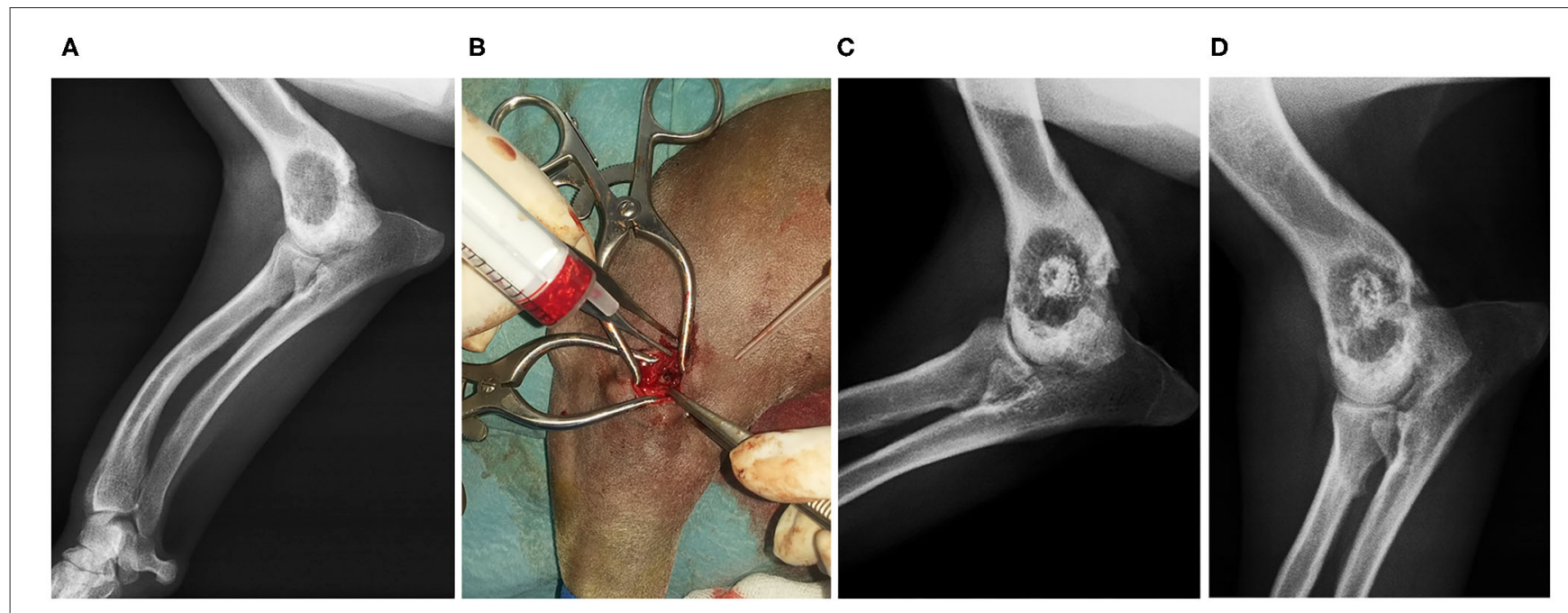

FIGURE 7 | Case 13. Preoperative radiographic image of humerus benign bone cyst (A); infiltration of the biomaterial (B); postoperative control 4 weeks image (C); postoperative control 8 weeks image (D).

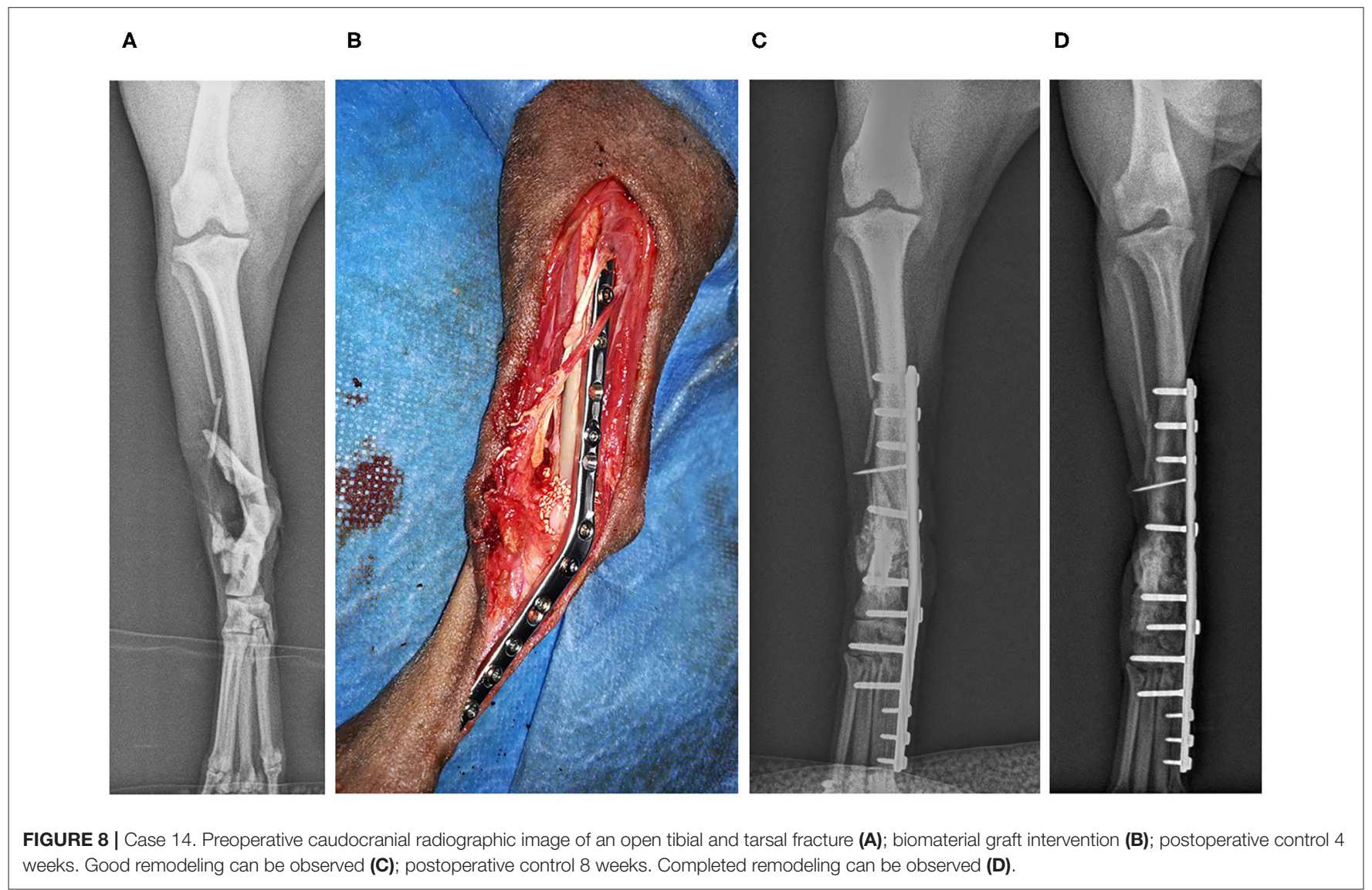

performed a reduction thereof, with an external fixator and a BV graft. At 8 weeks, a correct remodeling was observed radiographically, but the external fixator was not removed until after 12 weeks (Figure 9). In this case, fracture has healed with axial distortion with help of a BV.

Clinical Case 18. Dog, English setter breed, male of $27 \mathrm{~kg}$, presented severe carpal joint lesions. During the first procedure, 


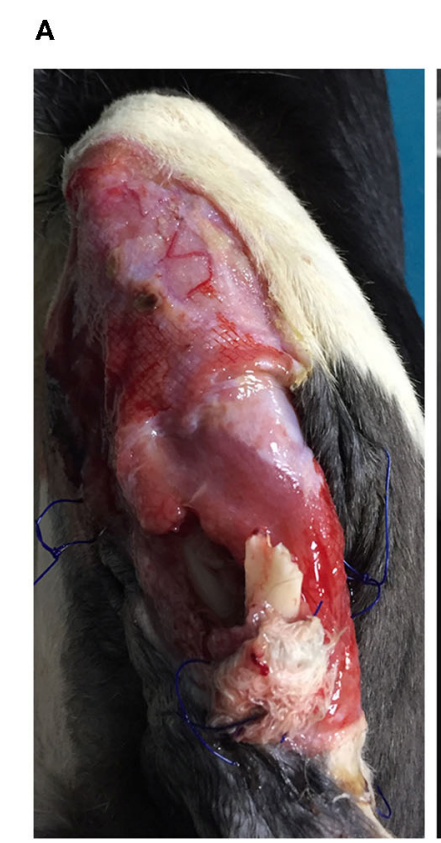

B

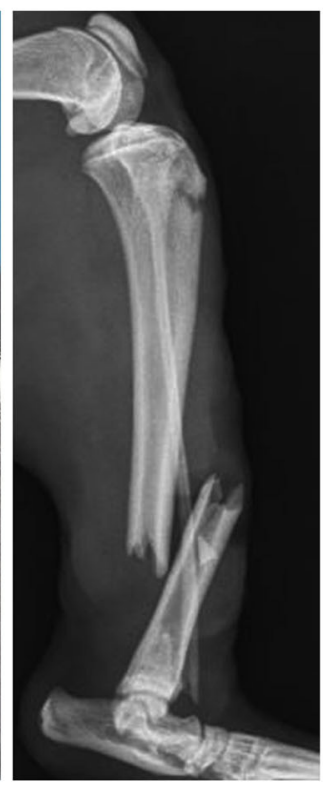

C

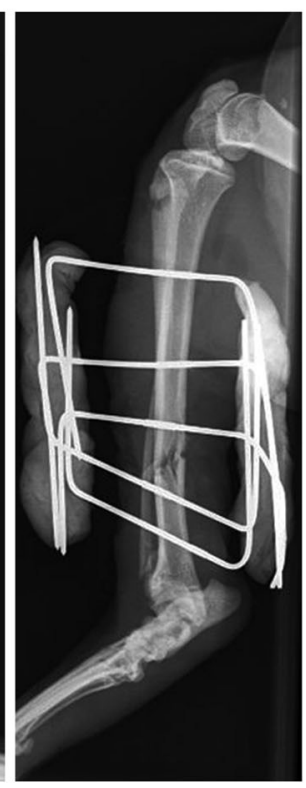

D

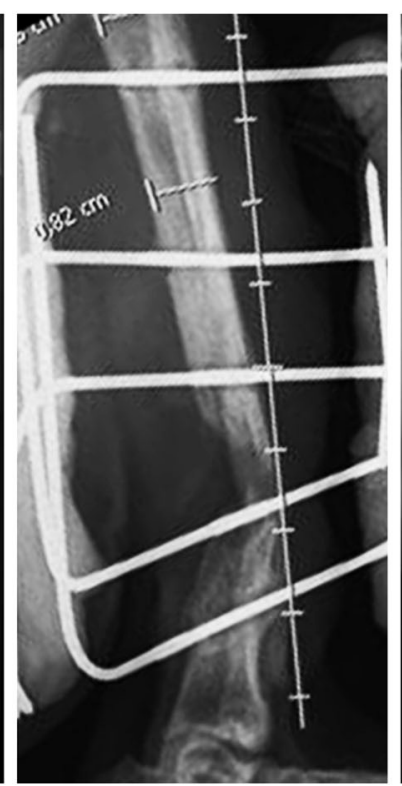

E

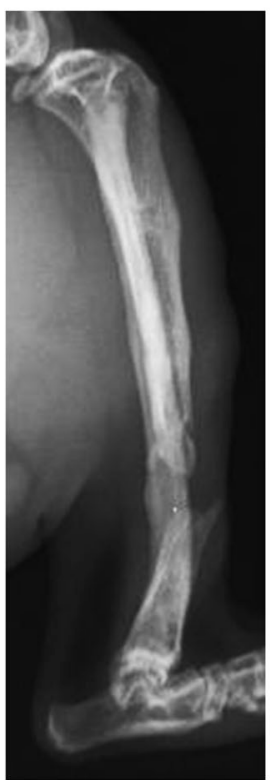

FIGURE 9 | Case 17. Open tibial and ulna fracture in a cat (A); preoperative radiographic image (B); postoperative radiographic image (C); postoperative control 4 weeks (D); postoperative control 12 weeks (E).

it was decided to place an internal fixation plate carrying out a carpal joint arthrodes, but 1 week after the procedure, the implants had to be removed because of infection. Three weeks later, the second procedure was performed, in which another plate was placed on the dorsal side, employing a BV graft, favoring a quick ossification. This allowed the removal of the implants earlier than usual (after $2 \frac{1}{2}$ months) and the beginning of rehabilitation.

Clinical Case 19. Mixed-breed dog, male of $17 \mathrm{~kg}$, presented with a multifragmentary fracture in the left femur. It was a very unstable fracture that applied load on the osteosynthesis implant in an extreme way, reducing its useful life. Therefore, a BV graft was added to promote rapid ossification and to reduce the load on the implant. BV met the expectations, and at 4 weeks, the patient showed a good evolution and perfect support, despite a very serious initial prognosis (Figure 10).

\section{DISCUSSION}

The present work demonstrated that porous globular bioapatites are viable for use in veterinary orthopedics. In all cases, there were no reports on adverse reactions at the grafting site or at systemic level. Except for case 11, there were no records of postoperative infection or foreign body reaction, regardless of the amount of grafted material. In case 11, because it was an old fracture by firearm and remitted from a less specialized clinic, the infection was not treated properly from the beginning, and the filling was not successful, producing a fistula after 2 weeks. Fractures caused by firearm represent a delicate situation in traumatology (36). The group that reviewed the case considered that, in this case, the use of the biomaterial had been contraindicated.

Fractures are the most common large-organ traumatic injuries (37). The normal and physiological reaction when a fracture occurs includes a series of events: initial inflammatory reaction, establishment of soft and subsequently hard callus and, finally, bone remodeling $(38,39)$. In cases where this physiological process does not occur, the surgery is indicated (40). Insufficient blood nutrition, a disease that systematically affects, or an infection of the bone callus can have a negative effect on the regeneration of the bone, which can trigger a non-union (41). In those situations where healing is not achieved, the use of bone substitutes is indicated (42). The autologous graft remains the gold standard in these types of situations, because it does not trigger immunological reactions, provides growth factors to help osteoinduction and is also part of the structure of the new bone $(40,43,44)$. Nevertheless, the use of autologous bone has disadvantages: longer anesthesia, the availability of autologous bone is limited, high morbidity of the donor site (risk of intraoperative bleeding, pain, possibility of stress fractures), increased chances of local infection, and risk of failure (5, 4547). It should also be noted that the amount of autologous bone collected and the viability of the cells collected are limited, which limits the application in situations where defects are critical (44). These disadvantages can be avoided by using synthetic bone substitutes instead of autologous bone. One of the advantages of these bone substitutes is their ease of storage $(43,48,49)$. In this report, we presented a series of cases in which the BV bone mineral substitute was shown to be an effective alternative and without adverse effects. This biomaterial is an excellent 
A

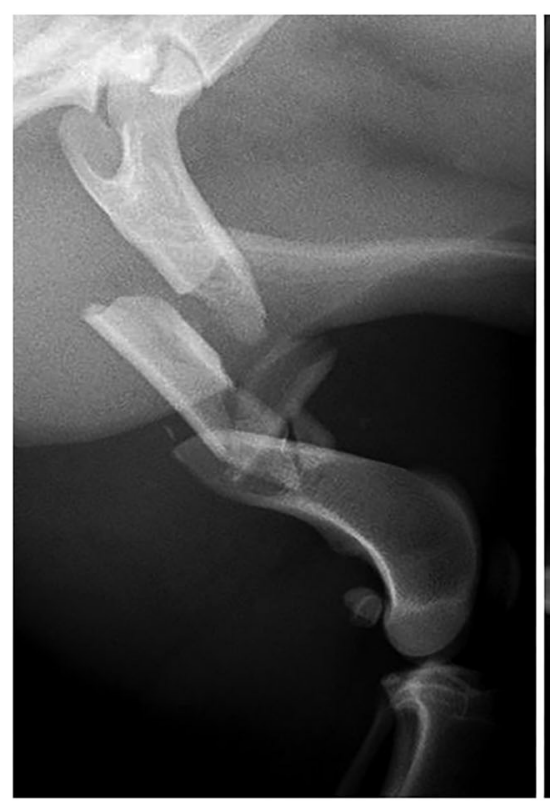

B

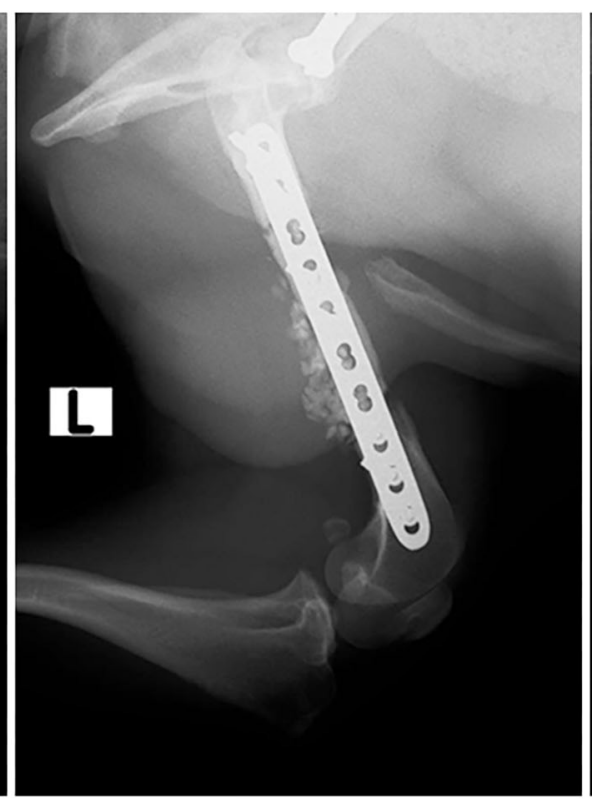

c

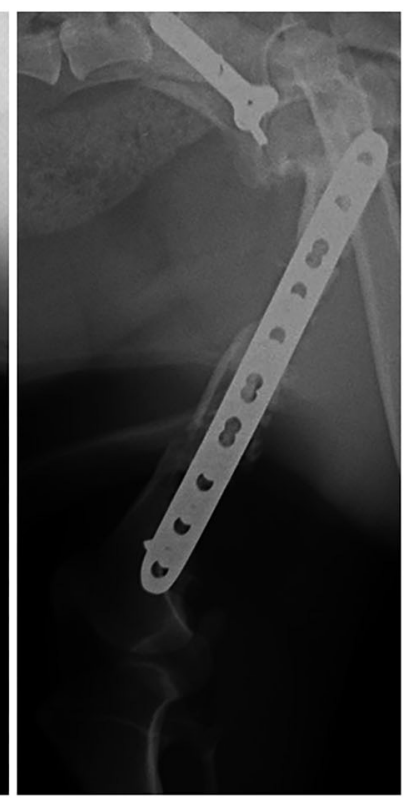

FIGURE 10 | Case 19 Preoperative radiographic image of a multifragmentary femoral fracture (A); postoperative control 4 weeks (B); postoperative control 12 weeks (C).

ceramic scaffold to promote and strengthen the process of bone regeneration. $\mathrm{BV}$ contains a large amount of $\mathrm{HA}$, which is one of the main components of the bone mineral matrix (50).

One of the challenges of using synthetic bone substitutes is maintenance within the defect. The mixing of $\mathrm{BV}$ with the patient's own blood achieved the desired effect, and the escape of the biomaterial was kept in the correct place. In addition, cell congregations within blood clots are bioactive potentials that favor the cure of the defect, promoting improved remodeling (51). The mixing of the biomaterial with platelet-rich plasma could also have been interesting, given the good results obtained in a study in which it was used for the treatment of fractures in dogs (29).

Other calcium phosphate ceramics have previously been used as bone substitutes in the veterinary field, obtaining good results in terms of improving the quality of life of the patient, speed of bone healing, and decrease in morbidity. In the mentioned research study $(4,48)$, the effectiveness of the material in appendicular and maxillary/mandibular bone defects was studied. The patients did not present any adverse effects at the local or systemic level, and the functional recovery was good in all cases, as in the present study. Despite being a preliminary study, in the present study, shorter consolidation times were obtained (5.94 vs. 9.07 weeks). However, controlled studies would be needed to give more weight to this premise.

Despite not having found statistically significant differences in the comparison of the consolidation time with sex, weight, and procedure, a slight trend can be observed in a shorter consolidation time in dogs of $<5 \mathrm{~kg}$ and in males.
The present study has some limitations. The diagnostic use of computed tomography would have been interesting to assess the density of postsurgical bone mineralization and at 12 weeks in the defect. The use of questionnaires in owners could have provided more quantitative data regarding the recovery of the animal. No controlled group was available. The statistical analysis of the age variable could have provided more quantitative data, but it could not be done because all ages were not available.

Seeing the promising results have been obtained in this preliminary study, it would be very useful to carry out controlled clinical trial to complement and provide more quantitative and comparative data about the study of this biomaterial.

\section{CONCLUSIONS}

In the present study, the viability of using globular porous bioapatites of marine origin in the veterinary field has been demonstrated. This biomaterial is presented as a very suitable candidate for orthopedic surgery in the veterinary field. It has been used successfully in 18 cases in which no local or systemic adverse reactions related to the biomaterial have been detected. Regarding the consolidation time, it is observed that the use of this biomaterial in dogs with arthrodesis and fractures can reduce it compared to other biomaterials.

However, controlled clinical studies are needed to evaluate the behavior of the biomaterial in different clinical settings. 


\section{DATA AVAILABILITY STATEMENT}

The relevant data for the investigation are collected in the text, tables and figures. The rest of the data are personal information of the patients' owners, being sensitive, and therefore, confidential.

\section{ETHICS STATEMENT}

The animal study was reviewed and approved by Xunta de Galicia. Written informed consent was obtained from the owners for the participation of their animals in this study.

\section{CONSENT FOR PUBLICATION}

All authors of this research consented to the publication of this paper.

\section{AUTHOR CONTRIBUTIONS}

PG-F, JS, and RO obtain and study the biomaterial and their properties (morphology, characterization, and composition) and choose the clinics where it was to be studied clinically. MG-G, $\mathrm{FM}$, and AG-C recompile all information about the cases and analyze the suitability of the treatment and its correct evolution.

\section{REFERENCES}

1. López-Âlvarez M, Vigo E, Rodríguez-Valencia C, Outeiriño-Iglesias V, González P, Serra J. In vivo evaluation of shark teeth-derived bioapatites. Clin Oral Implants Res. (2017) 28:e91-e100. doi: 10.1111/clr.12934

2. Mastrogiacomo M, Muraglia A, Komlev V, Peyrin F, Rustichelli F, Crovace $A$, et al. Tissue engineering of bone: search for a better scaffold. Orthod Craniofacial Res. (2005) 8:277-84. doi: 10.1111/j.1601-6343.2005. 00350.x

3. León B, Jansen JA. Thin Calcium Phosphate Coatings for Medical Implants. 1st ed. eds. León BJ. Jansen New York, NY: Springer New York. (2009). doi: 10.1007/978-0-387-77718-4

4. Campos JM, Sousa AC, Pinto PO, Ribeiro J, França ML, Caseiro AR, et al. Application of Bonelike $(\mathrm{R})$ as synthetic bone graft in orthopaedic and oral surgery in veterinary clinical cases. Biomater Res. (2018) 22:38. doi: 10.1186/s40824-018-0150-x

5. Pinto PO, Pinto PO, Atayde LM, Atayde LM, Campos JM, Campos JM, et al. Therapeutic strategies for bone regeneration: the importance of biomaterials testing in adequate animal models. In Advanced Composite Materials. Hoboken, NJ: John Wiley \& Sons, Inc (2016). p. 275319. doi: 10.1002/9781119242666.ch6

6. Chazono M, Tanaka T, Komaki H, Fujii K. Bone formation and bioresorption after implantation of injectable ?-tricalcium phosphate granules-hyaluronate complex in rabbit bone defects. J Biomed Mater Res. (2004) 70A:5429. doi: 10.1002/jbm.a.30094

7. Artzi Z, Weinreb M, Givol N, Rohrer MD, Nemcovsky CE, Prasad HS, et al. Biomaterial resorption rate and healing site morphology of inorganic bovine bone and beta-tricalcium phosphate in the canine: a 24-month longitudinal histologic study and morphometric analysis. Int J Oral Maxillofac Implants. (2004) 19:357-68

8. Piattelli M, Favero GA, Scarano A, Orsini G, Piattelli A. Bone reactions to anorganic bovine bone (Bio-Oss) used in sinus augmentation procedures: a histologic long-term report of 20 cases in humans. Int J Oral Maxillofac Implants. (1999) 14:835-40.

9. Boskey AL. Amorphous calcium phosphate: the contention of bone. J Dent Res. (1997) 76:1433-36. doi: 10.1177/00220345970760080501
MG-G carried out the manuscript design and drafted it. All authors have read and approved the final manuscript.

\section{FUNDING}

This research was partially financed by the INTERREG $\mathrm{V}$ Spain-Portugal_POCTEP program (0245 IBEROS1E and 0302 CVMARI1P), INTERREG-ATLANTIC AREA (EAPA_151/2016 BLUEHUMAN) and Xunta de Galicia (GAIN/IGNICIA BIOFAST-IN855A2016/06，GRC-ED431C 2017_51， ED431D 2017/13, and GRC ED431C 2017/37).

\section{ACKNOWLEDGMENTS}

The authors would like to thank BETA Implants for their collaboration. The authors also acknowledge the collaboration of the following veterinary clinics: CV Fauna, CV Miralbueno, CV Noso Can, SV Lepanto, CV Parque, CV Sauces and Vetpets.

\section{SUPPLEMENTARY MATERIAL}

The Supplementary Material for this article can be found online at: https://www.frontiersin.org/articles/10.3389/fvets. 2020.574017/full\#supplementary-material

10. Posner AS, Perloff A, Diorio AF. Refinement of the hydroxyapatite structure. Acta Crystallogr. (1958) 11:308-309. doi: 10.1107/s0365110x58000815

11. Ivanova TI, Frank-Kamenetskaya OV, Kol'tsov AB, Ugolkov VL. Crystal structure of calcium-deficient carbonated hydroxyapatite. Thermal Decomposition. J Solid State Chem. (2001) 160:3409. doi: 10.1006/jssc.2000.9238

12. Williams RA., Simkins DC. Bioquimica Dental Básica y Aplicada - Williams. 2a ed. México: Manual Moderno (1990)

13. Park JB, Lakes RS. Biomaterials : An Introduction. 3rd ed. New York, NY: Springer (2007).

14. Ratner B, Hoffman A. Biomaterials Science. Ratner B, Hoffman A, Schoen F. Lemons L, editors. London: Elsevier. (2004).

15. Lazaruc D, Forna DA, Forna NC. Bone regeneration material with a potential in gum regeneration. Mater Plast. (2016) 53:561-3.

16. Landi E, Uggeri J, Medri V, Guizzardi S Sr. Mg cosubstituted HA porous macro-granules: potentialities as resorbable bone filler with antiosteoporotic functions. J Biomed Mater Res Part A. (2013) 101A:2481-90. doi: 10.1002/jbm.a.34553

17. Shih TC, Teng NC, Wang PD, Lin CT, Yang JC, Fong SW, et al. In vivo evaluation of resorbable bone graft substitutes in beagles: histological properties. J Biomed Mater Res Part A. (2013) 101:240511. doi: 10.1002/jbm.a.34540

18. Soares PBF, Moura CCG, Chinaglia CR, Zanotto ED, Zanetta-Barbosa D, Stavropoulos A. Effect of titanium surface functionalization with bioactive glass on osseointegration: an experimental study in dogs. Clin Oral Implants Res. (2018) 29:1120-5. doi: 10.1111/clr.13375

19. Lee SB, Jung UW, Choi Y, Jamiyandorj O, Kim CS, Lee YK, et al. Investigation of bone formation using calcium phosphate glass cement in beagle dogs. $J$ Periodontal Implant Sci. (2010) 40:125-31. doi: 10.5051/jpis.2010.40.3.125

20. Ulery BD, Nair LS, Laurencin CT. biomedical applications of biodegradable polymers. J Polym Sci B Polym Phys. (2011) 49:832-64. doi: 10.1002/polb.22259

21. Izumisawa Y, Seno T, Abe R, Miyoshi K, Maehara S, Wakaiki S, et al. axial correction of pes varus by transverse-opening wedge osteotomy and t-plate fixation with beta-tricalcium phosphate $(\beta$-tcp) transplantation in Dachshunds. J Vet Med Sci. (2005) 67:437-40. doi: 10.1292/jvms.67.437 
22. Franch J, Díaz-Bertrana C, Lafuente P, Fontecha P, Durall I. Beta-tricalcium phosphate as a synthetic cancellous bone graft in veterinary orthopaedics: a retrospective study of 13 clinical cases. Vet Comp Orthop Traumatol. (2006) 19:196-204. doi: 10.1055/s-0038-1633001

23. Ferrario C, Rusconi F, Pulaj A, Macchi R, Landini P, Paroni M, et al. From food waste to innovative biomaterial: sea urchin-derived collagen for applications in skin regenerative medicine. Mar Drugs. (2020) 18:414. doi: 10.3390/md18080414

24. López-Álvarez M, Pérez-Davila S, Rodríguez-Valencia C, González P, Serra J. The improved biological response of shark tooth bioapatites in a comparative in vitro study with synthetic and bovine bone grafts. Biomed Mater. (2016) 11:035011. doi: 10.1088/1748-6041/11/3/035011

25. Boutinguiza M, Pou J, Comesaña R, Lusquiños F, de Carlos A, León B. Biological hydroxyapatite obtained from fish bones. Mater Sci Eng C. (2012) 32:478-86. doi: 10.1016/j.msec.2011.11.021

26. Whitenack LB, Simkins DC, Motta PJ. Biology meets engineering: the structural mechanics of fossil and extant shark teeth. J Morphol. (2011) 272:169-79. doi: 10.1002/jmor.10903

27. Enax J, Prymak O, Raabe D, Epple M. Structure, composition, and mechanical properties of shark teeth. J Struct Biol. (2012) 178:2909. doi: 10.1016/j.jsb.2012.03.012

28. Aguiar $\mathrm{H}$, Chiussi $\mathrm{S}$, López-Álvarez $\mathrm{M}$, González P, Serra J. Structural characterization of bioceramics and mineralized tissues based on Raman and XRD techniques. Ceram Int. (2018) 44:495-504. doi: 10.1016/j.ceramint.2017.09.203

29. López S, Vilar JM, Sopena JJ, Damià E, Chicharro D, Carrillo JM, et al. Assessment of the efficacy of platelet-rich plasma in the treatment of traumatic canine fractures. Int J Mol Sci. (2019) 20:1075. doi: 10.3390/ijms200 51075

30. Pruksakorn D, Rojanasthien S, Pothacharoen P, Luevitoonvechkij S, Wongtreratanachai P, Ong-chai S, et al. Chondroitin sulfate epitope (WF6) and hyaluronic acid as serum markers of cartilage degeneration in patients following anterior cruciate ligament injury. J Sci Med Sport. (2009) 12:4458. doi: 10.1016/j.jsams.2008.02.003

31. Nganvongpanit K, Boonsri B, Sripratak T, Markmee P. Effects of one-time and two-time intra-articular injection of hyaluronic acid sodium salt after joint surgery in dogs. J Vet Sci. (2013) 14:215-22. doi: 10.4142/jvs.2013.14.2.215

32. Eger CE. A technique for the management of radial and ulnar fractures in miniature dogs using translation pins. J Small Anim Pract. (1990) 31:37781. doi: 10.1111/j.1748-5827.1990.tb00484.x

33. Hamilton MH, Langley Hobbs SJ. Use of the AO veterinary mini 'T'-plate for stabilisation of distal radius and ulna fractures in toy breed dogs. Vet Comp Orthop Traumatol. (2005) 18:18-25. doi: 10.1055/s-0038-1632921

34. Gibert S, Ragetly GR, Boudrieau RJ. Locking compression plate stabilization of 20 distal radial and ulnar fractures in toy and miniature breed dogs. Vet Comp Orthop Traumatol. (2015) 28:441-7. doi: 10.3415/VCOT-15-02-0042

35. Aikawa T, Miyazaki Y, Shimatsu T, Iizuka K, Nishimura M. clinical outcomes and complications after open reduction and internal fixation utilizing conventional plates in 65 distal radial and ulnar fractures of miniature- and toy-breed dogs. Vet Comp Orthop Traumatol. (2018) 31:2147. doi: 10.1055/s-0038-1639485

36. Gustilo RB, Simpson L, Nixon R, Ruiz A, Indeck W. Analysis of 511 open fractures. Clin Orthop Relat Res. (1969) 66:14854. doi: 10.1097/00003086-196909000-00020

37. Einhorn TA, Gerstenfeld LC. Fracture healing: mechanisms and interventions. Nat Rev Rheumatol. (2015) 11:45-54. doi: 10.1038/nrrheum.201 4.164
38. Lopes D, Martins-Cruz C, Oliveira MB, Mano JF. Bone physiology as inspiration for tissue regenerative therapies. Biomaterials. (2018) 185:24075. doi: 10.1016/j.biomaterials.2018.09.028

39. Rajhans MS, Lokhande DU, Khandekar GS, Dhande PL, Gaikwad SV, Velhankar RD. Use of biphasic calcium phosphate in repair of long bone fracture with bone loss in dogs. Vet Pract. (2018) 19:73-5.

40. Khan Y, Yaszemski MJ, Mikos AG, Laurencin CT. tissue engineering of bone: material and matrix considerations. J Bone Jt Surgery-American Vol. (2008) 90:36-42. doi: 10.2106/JBJS.G.01260

41. Janicki P, Schmidmaier G. What should be the characteristics of the ideal bone graft substitute? Combining scaffolds with growth factors and/or stem cells. Injury. (2011) 42:S77-S81. doi: 10.1016/j.injury.2011.06.014

42. Sen C, Balci HI, Celiktaş M, Ozkan C, Gulsen M. Definitive surgery for open fractures of the long bones with external fixation. In: Basic Techniques for Extremity Reconstruction Cham: Springer International Publishing (2018). p. 107-128. doi: 10.1007/978-3-319-45675-1_9

43. Bohner M. Resorbable biomaterials as bone graft substitutes. Mater Today. (2010) 13:24-30. doi: 10.1016/S1369-7021(10)70014-6

44. Rogers GF, Greene AK. Autogenous bone graft. J Craniofac Surg. (2012) 23:323-7. doi: 10.1097/SCS.0b013e318241dcba

45. Nandi SK, Kundu B, Ghosh SK, De DK, Basu D. Efficacy of nano-hydroxyapatite prepared by an aqueous solution combustion technique in healing bone defects of goat. J Vet Sci. (2008) 9:183-91. doi: 10.4142/jvs.2008.9.2.183

46. Bai X, Gao M, Syed S, Zhuang J, Xu X, Zhang XQ. Bioactive hydrogels for bone regeneration. Bioact Mater. (2018) 3:40117. doi: 10.1016/j.bioactmat.2018.05.006

47. Ferracini R, Martínez Herreros I, Russo A, Casalini T, Rossi F, Perale G. Scaffolds as structural tools for bone-targeted drug delivery. Pharmaceutics. (2018) 10:122. doi: 10.3390/pharmaceutics10030122

48. Lobato JV, Hussain NS, Botelho CM, Maurício AC, Afonso A, Santos

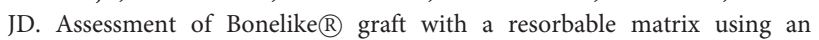
animal model. Thin Solid Films. (2006) 515:362-367. doi: 10.1016/j.tsf.2005. 12.153

49. Finkemeier CG. Bone-grafting and bone-graft substitutes. J Bone Jt Surgery American Vol. (2002) 84:454-64. doi: 10.2106/00004623-20020300000020

50. Anandan D, Jaiswal AK. Synthesis and characterization of human bonelike hydroxyapatite using Schiff's base. Ceram Int. (2018) 44:94017. doi: 10.1016/j.ceramint.2018.02.156

51. Schuckert K-H, Jopp S, Osadnik M. The use of platelet rich plasma, bone morphogenetic protein-2 and different scaffolds in oral and maxillofacial surgery - literature review in comparison with own clinical experience. J Oral Maxillofac Res. (2011) 2:e2. doi: 10.5037/jomr.2011.2102

Conflict of Interest: The authors declare that the research was conducted in the absence of any commercial or financial relationships that could be construed as a potential conflict of interest.

Copyright (C) 2020 García-González, Muñoz Guzón, González-Cantalapiedra, González-Fernández, Otero Pérez and Serra Rodríguez. This is an open-access article distributed under the terms of the Creative Commons Attribution License (CC BY). The use, distribution or reproduction in other forums is permitted, provided the original author(s) and the copyright owner(s) are credited and that the original publication in this journal is cited, in accordance with accepted academic practice. No use, distribution or reproduction is permitted which does not comply with these terms. 